\title{
Correction to: Comparison of Flow Estimators for Rotary Blood Pumps: An In Vitro and In Vivo Study
}

\author{
Anastasios Petrou, ${ }^{1}$ Daniel Kuster, ${ }^{1}$ Jongseok Lee, ${ }^{2}$ Mirko Meboldt, ${ }^{1}$ \\ and Marianne Schmid Daners ${ }^{1}$
}

${ }^{1}$ Product Development Group Zurich, Department of Mechanical and Process Engineering, ETH Zurich, 8092 Zurich, Switzerland; and ${ }^{2}$ German Aerospace Center (DLR), Institute of Robotics and Mechatronics, 82234 Wessling, Germany

Correction to: Annals of Biomedical Engineering (2018) https://doi.org/10.1007/s10439-018-2106-7

This erratum is to correct the third row of Table 2, where parameter $h_{2 h}$ is missing in the original article.

TABLE 2. Static and dynamic parameters identified based on static and dynamic experiments (Table 1, Dataset A of original article).

Estimator

Static coefficients

Dynamic coefficients

(3) PIPB

$$
\begin{aligned}
& h_{1}=5.809 \cdot 10^{-6} \frac{\mathrm{mmHg}}{\mathrm{rpm}} \\
& h_{2 h}=0.703 \frac{\mathrm{mmHg}}{(\mathrm{L} / \mathrm{min})^{2}} \\
& h_{3 h}=1.791 \frac{\mathrm{mmHg}}{\mathrm{L} / \mathrm{min}} \\
& h_{2 l}=-4.324 \cdot 10^{-7} \frac{\mathrm{mmHg}}{(\mathrm{L} / \mathrm{min})^{2} \mathrm{rpm}^{2}} \\
& h_{3 l}=4.570 \frac{\mathrm{mmHg}}{\mathrm{L} / \mathrm{min}}
\end{aligned}
$$$$
L=0.6084 \frac{\mathrm{mmHg}}{L / \mathrm{min} / \mathrm{S}}
$$

PIPB pump-inlet pressure-based.

Publisher's Note Springer Nature remains neutral with regard to jurisdictional claims in published maps and institutional affiliations.

Address correspondence to Marianne Schmid Daners, Product Development Group Zurich, Department of Mechanical and Process Engineering, ETH Zurich, 8092 Zurich, Switzerland. Electronic mail: marischm@ethz.ch

The original article can be found online at https://doi.org/10. 1007/s10439-018-2106-7. 